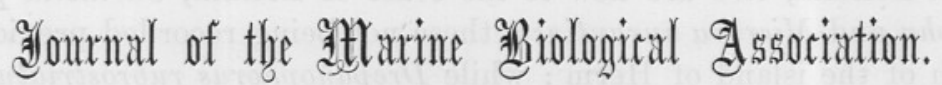

\section{A List of the Nemertines of Plymouth Sound.}

\author{
By
}

T. H. Riches, B.A.,

Caius College, Cambridge.

The present list, the result of observations made at intervals in the course of last year, was undertaken with the view of determining for embryological purposes the resources of the Sound with regard to this group. It includes the species obtained during a great part of the year 1892 .

Of the species recorded by McIntosh (1) as British, all but seven are here enumerated.* Of these seven, three, Amphiporus hastatus, Tetrastemma Robertianx, and Valencinia lineformis, are northern forms, occurring in Bressay Sound, Shetland, though one specimen of the first has been taken by Hubrecht (2) at Naples, and two by Joubin (4) at Roscoff. One, Borlasia Elizabethæ, is a southern form, not yet recorded north of Herm. The fourth, Meckelia asulcata, described by McIntosh as having a wide range, has not been met with by any other writer. The fifth, Nemertes carcinophila, though included among the British Nemertines, has apparently not been found on the British shores - at least the only localities mentioned by McIntosh are Messina and the coast of Belgium. The last, Amphiporus pulcher, is said " to be generally diffused round the British coasts in water eight to thirty fathoms deep," and seems to be common on the French coast and in the Mediterranean. I am inclined to think that a species which I describe below under the name of Amphiporus dissimulans, and which much resembles $A$. pulcher in appearance, has occasionally been taken for the latter.

Since the publication of the monograph I only know of one addition to the Nemertine fauna of Britain, the interesting Carinoma Armana i. This has unfortunately not yet been found here.

The total number of species here recorded is thirty-two. Four of these are new, Tetrastemma nigrum, T. immutabile, T. ambiguum, and Amphiporus dissimulans; one, Nemertes candida, is new to

* An eighth, the deep-water Cerebratulus marginatus, should be added to the number of the British species which I have not yet obtained.

NEW SERIES.-VOL, III, NO, I, 
Great Britain; two are new to the coast of Britain, Carinella polymorpha and Micrura aurantiaca, these not being recorded previously north of the island of Herm ; while Drepanophorus rubrostriatus, if, as I believe, identical with Amphiporus spectabilis, has not been met with north of Guernsey.

Of the parasitic forms I have only obtained Malacobdella. I have, however, examined several specimens of Galathea strigosa for Dieck's Cephalothrix Galathex, which he describes as parasitic upon the eggs and on the gills of this crustacean, and which I believe no other writer has seen. With regard to this species, I may remark in passing that it has been erroneously referred to the genus Carinella by Joubin and J. V. Carus (8). With the same want of success I have examined large numbers of specimens of Phallusia mammillata and other Ascidians for Joubin's Amphiporus vittatus and Tetrastemma Marionis, and an examination of female specimens in berry of Carcinus mænas has not resulted in finding Nemertes carcinophila.

In spite of the, in many cases, brilliant colours exhibited by . Nemertines, and although many of them are conspicuously marked, I have been unable to find any very definite relation in this respect to the surroundings. This want of relation is especially marked among the Tetrastemmidæ, which exhibit a very large amount of colour variation, and yet varieties the most divergent in this respect live together under apparently the same conditions. The genus Tetrastemma exhibits a very high degree of variation among its members, not only in colour, but also in marking and in general appearance unconnected with colour. These variations will be described in some detail below.

I will only now remark that varieties have been obtained which in many respects connect such well-marked species as $T$. candidum, $T$. vermiculatum, and T. melanocephalum.

The observations of Keferstein, Claparède, and others on the existence of otocysts among the Nemertea seem not to be in favour with most modern writers. Bürger (6), however, in a paper published in November, 1891, stated that he had observed otocysts of oval form which were situated one on each half of the brain in some unidentified enoplous Nemertines, which he found living in sand with Lineus lacteus and Amphioxus. A week later du Plessis (11) published a paper on the subject, in which he described a pair of otocysts which he found in a thin orange-red eyeless Nemertine of 15 to 20 $\mathrm{mm}$. in length, obtained under stones between tide-marks at Nice. These otocysts resembled those described by Bürger, and differed in many points from those observed by Claparède and Keferstein. On May 14th I found in sand on Drake's Island between tide-marks a few specimens of an armed Nemertine associated with Lineus lacteus. Each of these specimens exhibited a pair of otocysts of relatively large 
size, one on each ventral brain lobe just posterior to the ventral commissure. In the centre of each capsule was a single refringent otolith; no cilia could be detected. Like the two previous writers, with whose accounts I was not at that time acquainted, I failed to identify the bearers of these interesting structures. They were unfortunately lost before I had completed my examination of them. The following points, however, were made out:-Length from 1 to 2 $\mathrm{cm}$. Two of the specimens were pure white, the third was pinkish posteriorly ; brain conspicuously red; head rounded, with oval transparency in dorso-median line; generative organs ripe. Proboscis long, reaching to end of body, with anterior terminal pore, with median stylet and two accessory capsules, one containing several reserve stylets, the other only two ; mouth in front of ganglia ; eyeless. It seems to me very probable that Bürger, du Plessis, and myself have found the same species, since not only are the otocysts precisely the same in structure, but the accounts of the worms themselves, though meagre, are in agreement, and all of them are found living under the same conditions. Du Plessis attempts to correlate the presence of otocysts with the absence of eyes, but the latter condition is not infrequent among Nemertines, while the rarity of those with otocysts is sufficiently evinced by the general scepticism with which their existence has been regarded. Joubin, in his Poliopsis, describes structures which he at first took for otocysts, but afterwards found to be the blind ends of the ciliated canals of the side organs. The otocysts above mentioned cannot, however, be thus explained away.

The classification of the Nemertines has until lately been very defective. In 1890 Bürger, in his admirable paper on the anatomy and zoology of the Nemertea (5), very ably criticised Hubrecht's system, which he showed to be untenable, and proposed temporarily to return to that of Schultze. In the following year (6) he brought out a new scheme dealing with the primary subdivisions only. In his system these are four in number, and are based upon the situation of the nerve-stems. Last March (7) this system was further developed and carried into detail as regards three of the subdivisions. One of them, however, that corresponding to the Enopla of Schultze, was left for a future paper, which as far as I am aware has not yet appeared.

As this classification will be the one here adopted, it may be well to state at once its leading characters. According to Bürger's scheme the whole group consists of the four following orders:

I. PROTONEMERTINI (Carinella, Carinina, and Hubrechtia).Lateral nerves outside the circular muscular layer, situated either in the epidermis or beneath the basement membrane. 
II. MESONEMERTINI (Cephalothrix and Carinoma).-Lateral nerves have penetrated the circular muscular layer, and lie embedded in the longitudinal layer.

III. METANEMERTINI (Hoplonemertini of Hubrecht). Lateral nerves have penetrated the longitudinal muscular layer, and lie in the body parenchyma.

IV. HETERONEMERTINI (Schizonemertini of Hubrecht, together with the genera Eupolia and Valencinia).-Lateral nerves in the same position as in Carinella, but between the epidermis and the circular muscular layer a layer has developed consisting of glandcells, connective tissue, and longitudinal muscles, in which the nervestems lie.

Of these divisions, that of the Protonemertini is of course regarded as the oldest, and Bürger regards it as giving rise to the Mesonemertini through Carinella, and to the Heteronemertini through his new form Hubrechtia desiderata, for which he has established a new family, Hubrechtiadx. The Metanemertini he considers to have arisen from the Mesonemertini.

The subordinate changes concern the order Heteronemertini. This order is divided into two families,-the Eupoliadr, including the genera Eupolia and Valencinic ; and the Iineidx. The latter consists of two sections, the Micruræ and the Amicruræ, characterised by the presence or absence of a caudal appendage. To the Amicruræ belong the genera Micrura, Cerebratulus, and Langia. Of these the first two were united by Hubrecht under the name of the second. They are now again separated, the differentiating characters being those of general shape and mode of life.

In the above arrangement of the Lineidæ there is obviously a return to the scheme laid down by McIntosh. Hubrecht objected to the caudal appendage being regarded as a feature of generic value, and while thus abolishing the genus Micrura and including its species under Cerebratulus, he added to the latter all the shorter and broader species included by McIntosh under Lineus, with the result of establishing two genera, Lineus and Cerebratulus, with absolutely no point of difference except a very problematical ontogenetic difference. With our present knowledge there are, it appears to me, only two ways out of this difficulty. Either the genera Lineus and Cerebratulus must be fused into one, with the result of forming a very large genus-a method of escape suggested by Hubrecht himself $(\mathbf{3})$; or there must be a reversion to the McIntoshian system, which, with some alterations in detail, is the method adopted by Bürger. Of the two alternatives there can be no doubt that the last 
is much the better, and in spite of the absence of any striking structural differences between the genera Cerebratulus and Micrura, and only that of the caudal appendage between these and Lineus, this arrangement is much more convenient and natural.

With regard to the spawning periods of the various species my observations are not at present very complete. It may, however, be stated generally, that during the whole year some one or more species are breeding, and I was considerably astonished to find a large number of species with ripe generative products from late summer to the middle of December when I left Plymouth. During this period my specimens of $A$. dissimulans laid several batches of fertilized eggs, and all the species of Tetrastemma and many Schizonemertines were ripe, as was also the parasite Malacobdella. The tow-net, too, contained many pilidia of different species, as well as numbers of Cephalothrix larvæ. The presence of the latter was surprising, as I did not meet with any ripe adults later than August.

I have nothing to add to the observations of Joubin on the vertical distribution of these forms, with which my own substantially agree.

I have not attempted to give a list of the synonyms; a few only are given in the case of especially interesting species, or where there have been any recent changes in nomenclature.

The definitions of the different groups are those of Bürger.

\section{Order 1.-PROTONEMERTINI, Bürger.}

Brain and lateral nerves lie outside the muscular coat of the bodywall, either in the epidermis or beneath the basement membrane. Body-wall consists of epidermis and of a circular and longitudinal muscular layer. Mouth behind brain. Proboscis without a stylet.

\section{Family CARINELLIDA (McIntosh).}

\section{Genus CARINELLA, Johnston.}

1. C. polymorpha, Renier, Hubrecht.

$$
\begin{aligned}
& \text { Valencinia splendida, de Quatr. } \\
& \text { TubUlands polymorphus, Renier. } \\
& \text { Carinella annulata (pars), McIntosh. }
\end{aligned}
$$

Only one specimen has been obtained. It was dredged in 25 fathoms off Stoke Point on March 22nd, and its occurrence 
was recorded in the Journal of this Association for that month. As I then pointed out, it has not before been noticed on the British coast. I suggested, however, that a worm described by McIntosh as a variety of $C$. annulata, and obtained by him from the island of Herm, was probably identical with this form, and I am still inclined to think that this is the case. In the record to which I have alluded, I mentioned that upon very close examination under a lens extremely faint lines could be detected, apparently similar in position to those of $C$. annulata, except that the median ventral line was absent; these lines not being white, but distinguishable by the red colour being along their course somewhat paler than elsewhere. In the absence of the median ventral line this species resembles C. McIntoshii. In his specimen from Herm McIntosh describes a pale lateral line on each side, and faint transverse bars on the dorsum. These lines are not mentioned by other writers, nevertheless the general ground colour and the shape and size of the head sufficiently characterise my specimen as belonging to this species.

Distribution: Naples, but not common (Bürger) ; fairly common on French coast (Joubin).

\section{C. linearis (Montagu, MS.), McIntosh.}

Lineus linearis, Montagu, MS.

Carinella albida, Bürger.

The validity of this species has lately been called in question by Joubin, who is inclined to regard it as identical with Valencinia longirostris. There is no doubt great external similarity, but sections clearly reveal that the two specimens which I refer here belong to the genus Carinella, and not to Valencinia. The position of the nerve-cords between the basement membrane and the muscular coat of the body, and the absence of an outer longitudinal muscular layer, in which in Valencinia the nerve-stems lie, are quite conclusive as to this.

Both my specimens were dredged at the Duke Rock, the one on May 17th, the other on September 30th. Both were small, the second specimen measuring $1 \mathrm{~cm}$. in length and $0.5 \mathrm{~mm}$. in breadth. The first specimen was too mutilated to allow of measurement, but, judging from the size of the head, was much the same length as the other. The colour was milk-white in both cases, but in the first specimen there was a reddish tinge over the head. A transverse groove was present at the back of the head dorsally, but was difficult to trace. The head was broader than the body and somewhat spathulate, though its mobility was such that no very definite shape could be assigned to it, the snout being at one time 
pointed; at another rounded in outline. Passing from the point of the snout to the posterior region of the head was a median dark line, due apparently to a central opacity in this position, the rest of the head being relatively transparent. The mouth was a longitudinal slit in the position characteristic of the genus. The eyes were absent.

The short description which Bürger gives of his Carinella albida is so applicable to my specimens that I am inclined to regard it as identical with this species.

Distribution: South coast of England, and Lochmaddy in the Hebrides (McIntosh) ; Rizomi di Posidonia, Posilipo, not uncommon (Bürger).

3. C. annulata, Montagu.

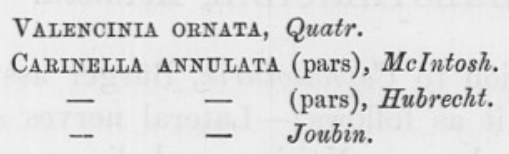

In the Carinella annulata of McIntosh, Bürger distinguishes two species, differing in colour, marking, size, and in the number and structure of the side organs.

Of the present species only one specimen has been obtained, and this was a fragment without head or tail of about $1 \mathrm{~cm}$. in length. It was, however, readily recognisable by the presence of a median ventral white line. This specimen was dredged in nearly 40 fathoms, about six miles S.E. of the Mewstone. The apparent rarity of this species is, I believe, solely due to its living at depths at present quite inaccessible to us. While at St. Andrews I obtained a large number of specimens which were found adhering to the long lines of the haddock fishermen, and were thus brought up from considerable depths.

4. C. McIntoshir, Bürger.

$$
\begin{gathered}
\text { Caringlia anndiata (pars), McIntosh. } \\
-\quad-\quad \text { (pars), Hubrecht. }
\end{gathered}
$$

Not uncommonly dredged in from 5 to 20 fathoms. Readily distinguishable from the last by its much smaller size, its white snout, the different relation of the white rings to each other, and the absence of a median ventral white line.

The chocolate variety, though rarer than the dark red, has been met with on several occasions. Many specimens obtained during 
the summer months had the white dots on the dorso-lateral regions of the middle and posterior parts of the body which mark the external openings of the generative organs. Whether the presence of these spots indicates sexual activity I do not know. Although many specimens were kept in captivity they did not spawn.

\section{Order 2.-MESONEMERTINI, Bürger.}

The lateral nerves are pushed down into the body musculature. The body-wall consists of epidermis, a circular and a longitudinal muscular layer. Mouth behind brain. Proboscis without a stylet.

\section{Family CEPHALOTHRICID $A$, McIntosh.}

To this family, in addition to Cephalothrix, Bürger assigns Carinoma. He characterises it as follows:-Lateral nerves situated in the longitudinal muscular layer. Neither cephalic grooves, clefts, nor side organs present.

The negative characters here assigned, and which are repeated in the definition of the genus Cephalothrix, can scarcely be accepted in view of the recent positive statement by Joubin of the existence of side organs in Cephalothrix linearis, strengthening as it does the earlier assertion of Barrois (9) to the same effect. In 1877 Barrois stated, "Les organs latéraux du Cephalothrix linearis sont, en général, peu accusés ; c'est là, ce qui fait que plusieurs auteurs les ont laissé passer inaperçus et ont dessiné le Némerte comme en étant dépourvu; je me suis assuré que c'était là une erreur: ces organes existent très-bien chez le Cephalothrix adulte et y présentent, avec le système nerveux, une disposition analogue à celle des Lineus."

This statement has been persistently neglected, but now that these organs have been again described, and this time with figures, their existence can scarcely be doubtful.

\section{Genus CEPHALOTHRIX, Oersted.}

5. C. linearis, Rathke, Oersted.

This species appears to be much less common than the next, and reaches a very much greater size. Though I have never found any specimens of the gigantic length of $50-60 \mathrm{~cm}$., such as Joubin describes are obtained on the French coast, I have had several 
varying from 10 to $15 \mathrm{~cm}$. in length. A few individuals have been obtained by dredging in the deeper water outside the Breakwater, but the bulk of my specimens have been obtained in the sand between tide-marks at Rum Bay. They have not yet been found in a similar situation in any other locality. Joubin states that his specimens came from black muddy sand, and he contrasts this species with $C$. bioculata in this respect, as, according to him, the latter lives in pure yellow sand. This difference of habitat in the case of the two species does not appear to hold good for Plymouth forms. Here both species are found in clean coarse sand, and I have occasionally found $C$. bioculata in black mud.

\section{C. Bioculata, Oersted.}

This common species may be obtained almost everywhere between tide-marks. As I have already said, a few specimens have been occasionally found in black mud, but the majority in clean, coarse sand. Large numbers live among corallines, and may be captured by collecting the latter. Unless Bürger's C. hymenæus is a variety of this species, it does not occur at Naples, but the difference between them is very slight, consisting as regards $C$. hymenæus in a reduction of the red pigment on the head to the two red specks, and the presence of grains of blue pigment in the latter. A difference of habitat is also mentioned, C. hymenæus never being found in sand, but associated with Tetrastemma coronatum. At Plymouth Tetrastemma coronatum is abundant among the corallines in tide-pools, where it is associated with the present species.

The breeding period lasts from early spring until the beginning of autumn. Ripe specimens were first found in April, and none were found later than August. As I have already mentioned, pelagic larvæ were obtained from the tow-net as late as December. The largest of these was $3 \mathrm{~mm}$. long, and was provided with an additional pair of marginal lappets, situated between the pair figured by McIntosh and Barrois and the anterior extremity. The eyes were situated at the margin of the head, and relatively far back. Some days after the capture of this larva it gave up pelagic life, and sank to the bottom of the vessel. About this time the eyes began to atrophy, and very shortly the adult appearance was reached. I have succeeded in getting this species to breed in captivity, and hope soon to publish an account of its development. 


\section{Order 3.-METANEMERTINI, Bürger.}

The lateral nerves have completely broken through the muscular coat of the body-wall, and have come to lie within it in the parenchyma. The body-wall consists of epidermis, a circular muscular layer, and a longitudinal muscular layer. The mouth is situated in front of the brain. The proboscis, with few exceptions, is provided with a stylet.

\section{Family AMPHIPORID $\mathrm{A}$, Hubrecht.}

\section{Genus AMPHIPORUS, Ehrenberg.}

\section{A. LACTifloreus, McIntosh.}

Nearly as common as $L$. obscurus. Lives between tide-marks under stones. The arrangement of the eyes in two groups on each side, the posterior group generally forming a triangle, with one eyespeck (that most remote from the snout) much larger than the rest, is very characteristic.

The colour is very variable; many shades of white and whitish pink are represented, but the commonest colour is perhaps light brown. I have never met with a green variety, though this seems common on the French coast, and has been found at Guernsey.

Ripe specimens and eggs were found in the early spring.

\section{A. Dissimulans, n. sp.}

I have established this species for a very abundant Amphiporus which I at first took to be Amphiporus pulcher. It agreed with this species in the general shape of the body, with its oar-like tail; in the broadly spathulate pointed head, so different in appearance from that of A. lactifloreus, and, in contrast to the latter, sharply separated from the body; in the arrangement of the eyes, which are never divided into groups; and in habitat occurring only in from 15 to 20 fathoms.

The average length is $5 \mathrm{~cm}$. ; the colour is variable, but most frequently is a very pale pink, the pink being rather pronounced anteriorly, but posteriorly passing into a bluish tint. The tip of the snout has a central papilla, from which an opaque line passes back a short distance. The eyes are very numerous; in one specimen I counted forty on one side. The brain can be seen as a red object shining through the skin, but it is not so conspicuous as in A. lactifloreus. 
The arrangement of the cephalic grooves is somewhat peculiar, it is the same as that described by Joubin in $A$. pulcher.

In the characters just given, the specimens included here do not seriously differ from $A$. pulcher, but they differ essentially in the structure of their proboscis, which resembles that of A. lactifloreus, while that of $A$. pulcher, according to the description given by McIntosh, is widely different, and in the situation of their side organs, which is in front of the brain as in A. lactifloreus, and not behind it.

These differences in proboscis structure and in position of the side organs rendering it impossible to assign these specimens to the species A. pulcher, it yet remains whether they ought not to be considered varieties of A. lactifloreus. But against this view are the characters above given of the shape of the head and of the tail, the number and arrangement of the eyes, the position of the cephalic grooves, and the difference of habitat, A. lactifloreus being a shallow water form, and these specimens being never obtained in less than 15 fathoms.

It seems very probable that this species has been occasionally described as A. pulcher. Joubin, for instance, in describing the specimens at Roscoff and Banyuls says nothing of the peculiar structure of the stylet region of the proboscis, so characteristic of the latter species, nor does he mention the situation of the side organs. On the other hand, he says that he has not seen the secondary cephalic grooves described by McIntosh ; and his figure of the arrangement of the primary grooves is, as has been said, perfectly applicable to this species. While, moreover, McIntosh finds only twenty-three eyes on each side of the head, Joubin describes as many as thirtyfive or forty-five.

Ripe specimens occur in the spring, but are more common in October, at a time when $A$. lactifloreus is not breeding.

The only locality from which this species has hitherto been obtained is the Millbay Channel, where it occurs in considerable numbers.

\section{A. Bioculatus, McIntosh.}

Only one specimen of this northern species has been obtained. It was dredged in Millbay Channel on November 18th, with many examples of the last species. Its length was about $1 \mathrm{~cm}$. In colour it was somewhat different from that of specimens previously described, being a milky white, while the Shetland specimens were dull orange, and the two obtained at Roscoff were green. The description and figure of the head given by Joubin exactly apply to the present specimen.

This species has not yet been found in the Mediterranean, and this is the only record from the coast of England. 


\section{Genus DREPANOPHORUS, Hubrecht.}

10. D. Rubrostriatus, Hubrecht.

AMphiporus spectabilis, McIntosh.

This species has been the centre of much controversy, and there is still some confusion regarding it. The controversy concerns the identity or non-identity of the Naples Drepanophorus rubrostriatus with the Atlantic Amphiporus spectabilis of McIntosh. Hubrecht is of opinion that they are not identical, and he accuses McIntosh of having referred the anatomical points which he obtained from Mediterranean forms to Atlantic specimens, thus, according to Hubrecht, " confounding specimens, species, and even genera." As far as I understand Hubrecht's position, he maintains that there are two species belonging to distinct genera, the one being an Amphiporus, the other a Drepanophorus, and that these two present great external similarity, and have hence been confounded; that the Drepanophorus is restricted to the Mediterranean; and that the Atlantic form described by McIntosh as Amphiporus spectabilis is distinct from it, being identical with the Amphiporus splendidus of Keferstein and Barrois, and not with the Cerebratulus spectabilis of De Quatrefages, which he regards as synonymous with his own species.

Joubin, on the other hand, who has had the advantage of working at both Atlantic and Mediterranean Nemertines, is of opinion that the two are identical, though he does not appear to have had anatomical evidence for this.

Apart from the very remarkable curved stylet in the proboscis, the genus Drepanophorus is characterised by the presence of transverse cæca belonging to the proboscis sheath, these cæca being arranged metamerically. And this character alone has been used by Hubrecht in referring some of his "Challenger" specimens to this genus. Now the specimens that I have obtained at Plymouth, which are in complete agreement with the description given by McIntosh of Amphiporus spectabilis in his monograph (his views as to the proboscis - which, however, he afterwards admitted to be erroneousalone excepted), exhibit very clearly in sections these metameric cæca, so that no doubt can remain that they belong to the genus Drepanophorus. This being so, is not the identity of the Amphiporus spectabilis of McIntosh with Hubrecht's Drepanophorus rubrostriatus established?

Five specimens have been found. The first came from weeds dredged in Cawsand Bay on November 11th. It was $2 \mathrm{~cm}$. in length, and exhibited the bright red stripes shown in Joubin's 
figure. All the rest were dredged at Stork Point during the same month, and were found inside the honeycombed stones with which the bottom is there strewn. These specimens were considerably larger than the first, the largest being something over $6 \mathrm{~cm}$. in length and the smallest between 3 and $4 \mathrm{~cm}$. In all these the colour was much paler than in the Cawsand Bay specimen, the red lines being represented by buff-coloured lines, and the intermediate lines being grey instead of pale pink. In these larger individuals the generative organs were ripe.

This species has not previously been recorded so far north. It occurs on the Atlantic shores of France, but is much more common in the Mediterranean. A single specimen was found at Guernsey by McIntosh.

\section{Family TETRASTEMMID $\approx$, Hubrecht.}

\section{Genus TETRASTEMMA, Ehrenberg.}

As has been already remarked, this genus is characterised by the very high degree of variation which its members exhibit. It is for this reason in many cases extremely difficult to identify a given species, or to come to anything like a satisfactory conclusion as to the amount and kind of difference which justifies specific separation. Such conclusions as are expressed by the recognition of the following species are provisional. They are, however, based on a consideration of the kind and degree of variation exhibited in each case.

\section{T. Flavidum, Ehrenberg.}

This species is very different in appearance from the other members of the genus, and, unlike them, exhibits very little variation. It is very common, and may be found between tide-marks, but it is obtained in larger numbers by dredging in from 5 to 20 fathoms. The Duke Rock and Millbay Channel are favorable localities.

Ripe specimens occur in autumn.

\section{T. Dorsale, Abildgaard.}

This very common species seems to inhabit every level from Joubin's second zone to his fifth. It was especially common in spring and early summer among the Zostera in Cawsand Bay. Later in the year, however, it became less common in this locality, and late in the autumn it was quite the exception to find a single individual there, when a small Terebellid seemed to have taken its place. 
Several varieties have been met with, agreeing with those described by other writers, but all were marbled. This species agrees with the two following, and differs from all other Tetrastemmas in the rounded shape of the body, and in the absence of a well-defined head region, so characteristic of the remaining species.

The breeding season is the autumn.

\section{T. NIGRUM, n. sp.}

I describe under this name a species which I at first considered as a variety of the last. Like Tetrastemma dorsale it has a rounded body, and there is no well-marked head ; but though highly variable in marking, it yet maintains certain characteristics to which no varieties of $T$. dorsale that I have met with in any way approach. The general ground colour, which is a pale yellow, may be entirely or partially hidden by a strong development of a very dark brown, almost black pigment, which is in the form of a close network. This dark pigment either covers the dorsal surface of the animal entirely, rendering it quite black to the naked eye, or the median dorsal line is left uncovered, which thus appears as a median yellow stripe. This stripe passes from the anterior to the posterior extremity, and is generally interrupted, but quite irregularly, by bridges of the dark pigment stretching across it. The breadth of the stripe is very variable, both in different animals and in different regions of the same animal, and its edges are much frayed. The cephalic grooves are more apparent than in the case of ' $T$. dorsale, owing to the absence of the dark pigment at their edges; but the eyes, which are reddish, have the same position, and are deeply placed. The stylet region of the proboscis resembles that of T. dorsale, but there is considerable variability in the shape of the stylet handle.

This species is most commonly found on Codium, which it in some degree resembles in colour, enough at least to make it difficult to find. I have, however, obtained it from weeds of various kinds, in the Laminarian zone. The average length is $1 \mathrm{~cm}$.

\section{T. immutabile, n. sp.}

The specimens brought together under this name are perhaps identical with one described by Joubin as a variety of $T$. dorsale. From this species, however, they differ at least as much as many species (which are regarded by every one as distinct) do from each other. I am, moreover, inclined to regard them as constituting a distinct species, because in spite of the variability of $T$. dorsale I have met with no variations which in any way approach them in 
colour and marking, and they, on the other hand, are singularly invariable.

The length ranges from $5 \mathrm{~mm}$. to $1 \mathrm{~cm}$. The body is rounded, and ends abruptly both anteriorly and posteriorly as in $T$. dorsale; the head, however, is more apparent than in the latter, owing to the slight amount of pigment there distributed. The ground colour is yellow, with a sprinkling of orange-red granules, which are strongly concentrated in the median dorsal line, forming a stripe of chocolate colour, beginning just in front of the anterior pair of eyes, and passing backward to the posterior end of the body.

The eyes are black, and similarly situated to those of $T$. dorsale. Many specimens have been found in the coralline pools at Wembury Bay, and they are also met with among the weeds in the second and third zones, and dredged at the Duke Rock. In all these places they are associated with other species of Tetrastemma, including $T$. dorsale.

\section{T. candidum, O. F. Müller, Oersted.}

Agrees with the remaining species of this genus, and differs from the last three in its more or less flattened body, in marked contrast to the rounded body of $T$. dorsale and its allies, and in its sharply separated spathulate head. The species now to be considered are also characterised by their excessive variability. Only one specimen resembling the type form of McIntosh has been obtained; this was found by Mr. Garstang in sand between tide-marks at Rum Bay on the 21 st of July.

The reddish and yellow varieties are not uncommon. They are found, though in small numbers, in Cawsand Bay among the weeds. Larger specimens are dredged in 5-20 fathoms, and they appear to be more numerous at the greater depth. Thus specimens have been dredged at the Duke Rock, and in Millbay Channel, but the majority have come from Stoke Point, where they seem to live associated with Lepralia, which they closely resemble in colour. The positive points characterising this species seem to consist in the shape of the head, which is more rounded than in the other members of the genus, in the definiteness of the cephalic grooves, which give the head a very characteristic appearance, and in the clearness and distinctness of the eyes, which are round and black. But in these as in other points there is great variation, and some varieties seem to form a series bridging the gulf separating this from the succeeding species. An interesting instance of this variation was exhibited by a Tetrastemma obtained in October, and which, while agreeing with the reddish variety of the present species in all other points, differed with regard to the anterior pair of eyes, which, instead of being 
compact and round, were broken up into two little masses of minute specks, invisible except under the microscope. Immediately above these disintegrated eyes on each side was a slight aggregation of orange pigment granules which passed back towards the posterior pair, but ended just in front of the anterior grooves. In this and the following species there is a tendency towards the formation of a median dorsal white line, passing from the snout to the posterior extremity. In this specimen the white line was conspicuous, though somewhat interrupted in its course posteriorly, and on the snout it was continuous with an oval patch of the same white pigment.

In the slight development of pigment between the anterior and posterior eyes, the specimen just described exhibited a character which reappeared in another obtained from weeds collected at Redding Point. In this specimen, which was of a green colour and much resembled the type form, the anterior eyes were normal, and close behind them on each side was a little patch of orange pigment which, as in the last case, passed backwards towards the posterior eyes, becoming imperceptible behind the anterior grooves. A thin median dorsal white line passed backward from the snout, but came to an end just behind the posterior eyes. The shape of the head of this specimen, and the distinctness of the eyes, as well as the structure of the stylet region of the proboscis, clearly indicated that it belonged to this species. In this development of pigment between the anterior and posterior eyes, however, there is the suggestion of a transition to T. vermiculatum. This suggestion gathers force with the finding of varieties in which the characteristics of T. vermiculatum become more pronounced, and those of the present species less marked, until it becomes difficult to determine whether a given specimen shall be considered a variety of this or that species. One such specimen was obtained on the 21 st November ; it was $1 \mathrm{~cm}$. long, and in colour resembled the yellow variety of this species; the anterior eyes were round and distinct; the posterior, though equally distinct, were much smaller and closer together; the anterior and posterior eyes of each side were connected by a band of bright orange pigment; the cephalic grooves were not so distinct as they usually are in this species, and the head was not so rounded. In this particular specimen the proboscis stylet resembled neither that of this nor any other species in particular; but in another, which exhibited all the above-mentioned characters, the stylet was like that of $T$. vermiculatum, the handle being much swollen at its base.

A still nearer approximation to $T$. vermiculatum was reached by an individual dredged from Millbay Channel on the 25th of November, which should perhaps be regarded as a variety of that species. This specimen, a ripe male $15 \mathrm{~mm}$. long, was of a brighter 
yellow than the last, the colour being intensified by the presence of scattered granules of orange pigment; the head was somewhat narrow and elongated, the eyes very distinct, the posterior being very slightly smaller than the anterior, and the four forming a rectangle. The cephalic grooves were very distinct; the anterior and posterior eyes on each side were united by a band of dark brown pigment; there was a median dorsal white line on the head passing from the snout to a point just behind the posterior grooves; the proboscis stylet resembled that of $T$. vermiculatum.

According to McIntosh this species breeds in April and May as well as in the autumn. I have only found ripe specimens in autumn.

\section{T. vermiculatum, De Quatr., McIntosh.}

This is a fairly common species, living in weeds between tidemarks, and also in water of 5 to 20 fathoms, being frequently dredged with stones at the Duke Rock and Millbay Channel. Joubin finds that the young forms are without the pigment uniting the anterior and posterior eyes, and observes that the dorsal white line is a preferable character in distinguishing this species. On this point I cannot agree with him, as, on the one hand, I have obtained many specimens which are without the median dorsal white line; and on the other, such a line, as I have already said, appears in an erratic manner on individuals of all these species, sometimes extending from snout to tail, sometimes limited to the head, and sometimes being a mere row of white dots. With his other remark, that the oval head "est assez caractéristique," I quite agree. As in the case of the other members of this genus, the breeding period is late autumn and early winter, but, as in the last species, McIntosh found ripe specimens in spring and early summer.

\section{T. melanocephalum, Johnst.}

T. MELA NOCEPHALUM, Hubrecht.

T. CORONATUM, Hubrecht.

I agree with Joubin in regarding Hubrecht's two species, T. melanocephalum and $T$. coronatum, as really forming one, and I shall be surprised if his $T$. diadema does not turn out to be a variety of this species also. I have not found any specimens that perfectly agree with Hubrecht's description of the last-mentioned species, but the description given by Joubin of $T$. diadema is quite applicable to what I regard as a variety of $T$. melanocephalum. That the specimens to which I refer really belong to this species there can be little doubt, the variations by which they are connected to the type form being so numerous.

NEW SERIES, - VOL, III, NO, I. 
This species lives under the same conditions as the other members of the genus, and is found associated with them among weeds between tide-marks and on stones dredged in 20 fathoms.

The greater number of specimens are various shades of yellow, but a bright green variety is found in the coralline pools of Bovisand Bay. It is this variety which I think Joubin describes as T. diadema.

The green specimens are the longest of this species I have yet met with, commonly reaching $3 \mathrm{~cm}$. in length. The pigment patch is dark brown and quadrangular in shape, with a slight tendency to concavity in front and convexity behind. There are three pronounced patches of white, two in front of the dark patch, one on each side of the head and somewhat triangular in outline, and one behind it stretching across the breadth of the posterior part of the head. I have not determined whether the white patches are pigment patches, or whether they are due to the aggregation of fatty particles, as Hubrecht suggests. The eyes are approximately of the same size, and are very distinct, the anterior pair being situated just in front of the dark patch, within which, however, they are in some specimens included.

Many specimens of the yellow variety are met with agreeing generally with the above, the majority not reaching more than $15 \mathrm{~mm}$. in length (though a single specimen was found as long as $4 \mathrm{~cm}$.), and exhibiting great inconstancy in the amount and distribution of the white patches, which are sometimes absent altogether, as well as in the size and intensity of the dark patch.

A common variety is that in which the pigment patch is represented by a sprinkling of brown granules over a roughly quadrilateral area situated between the two pairs of eyes. Before this pigment are two small white patches, and behind is a transverse white patch, behind which again the posterior eyes are placed. In this variety the white granules which exist, distributed irregularly over the body of most specimens, become regularly arranged along the median line, forming a series of disconnected transverse bars passing from the posterior white patch on the head to the fan, composed of radiating white lines, which is found at the tail of nearly all the yellow varieties. In one specimen I have met with a still further stage of this tendency for the white particles to aggregate along the median line. In this, which had the broad dark patch of the type form, in front of and behind which some white granules were scattered, there was a very definite and conspicuous thin white median line passing from just behind the posterior eyes to the tail.

In many, if not most specimens with a broad, well-defined, dark pigment patch on the head, those portions of the pigment which are situated in the line uniting the anterior and posterior eyes are con- 
spicuously darker than the median portion. This tendency is expressed more strongly in some specimens than in others, until a condition is reached in which the median portion has almost entirely disappeared, leaving only a thin bridge which joins the posterior ends of two masses of pigment which extend from the anterior to the posterior eyes. Behind the pigment bridge there is a band of white separating it from the posterior eyes, but there is no white on the anterior portion of the head. A median aggregation of granules is present on the body, forming a white dotted line passing from the white head patch to the tail fan.

A specimen which was dredged in the Hamoaze near the "Royal Adelaide" on December 14th represents the final term of the series, and follows the last very closely. In this individual the pigment bridge has completely broken down, so that in this case the head is characterised by two dark patches passing from the anterior to the posterior eyes, one on each side. Between the posterior eyes there is a patch of white, but this is much smaller than in the last specimen. The posterior eyes are slightly smaller than the anterior (which was the case in the last variety), and are slightly closer together. This individual undoubtedly belongs to this species, both on account of the fact that it belongs to an entire series reaching up to the type form, and also because in the presence of the white patch between posterior eyes, in the shape of the head and the condition of the stylet region of the proboscis, it exhibits most characteristic melanocephalous features. Nevertheless this arrangement of pigment is certainly suggestive of a transition towards $T$. vermiculatum, and especially recalls varieties described as intermediate between $T$. candidum and T. vermiculatum.

Only one case has come under my notice in which any relation could be detected between the colour of the animal and that of its surroundings. It was that of a specimen found among red weeds. The colour of this individual was remarkable, differing entirely from any other met with. The ground colour was a greenish yellow, but this was covered superficially by minute red-brown pigment granules, the result being the production of a colour remarkably similar to that of the weeds in which it was found. The redbrown granules were concentrated on the head to form the usual quadrate patch, the edges of which were not sharply defined, and the patch itself was reddish, not black. This animal, which was $1 \mathrm{~cm}$. long, was a female containing ova.

\section{T. АMbiguUM, n. sp.}

Under this name I include a few specimens found in November which have many points of agreement with T. Robertianx, as a

Not uncommon. Almost restricted to the Breakwater, where it is found at low tide among the roots of Laminaria and in the cavities of stones. It has a wide distribution, ranging from the north of England to Madeira. 
variety of which species I was at first inclined to regard them. I am induced to separate them, however, because of the absence of the peculiar marking which is so characteristic of that species.

The length is about $1 \mathrm{~cm}$. The head, which is very distinct from the body, is very broad at the level of the entrance to the side organs, and in shape resembles that of $T$. melanocephalum. The anterior eyes are at least twice as large as the posterior. All four are of a brown colour, of irregular shape and not well defined. The ground colour is a pale yellow. On the dorsal surface there is a considerable development of reddish-brown pigment, which covers the whole of this surface of the body from just behind the posterior grooves to the tail.

The proboscis stylet handle is of the shape described by McIntosh as characteristic of T. Robertianæ.

I also refer here a specimen which I found the same month, which exhibited some differences from those above described. The length was $15 \mathrm{~mm}$., the colour a uniform pale yellow. The general shape and the relation of head and body was the same as in the type form. The eyes were black and fairly distinct, the anterior being nearly twice the size of the posterior. The stylet handle resembled that of $T$. vermiculatum rather than that of $T$. Robertianæ.

All these specimens had ripe generative organs.

\section{Genus PROSORHOCHMUS, Keferstein.}

McIntosh characterises this genus as follows:- "Eyes four, not forming a rectangle; snout dimpled, and furnished with a transverse superior lobe. Ovo-viviparous." Of these three characters the first is scarcely available, as there is a general tendency towards this condition in the genus Tetrastemma, a tendency so great that in almost every species there are many individuals with the posterior eyes closer together than the anterior. McIntosh himself is not inclined to attach much value to the third character, as he says "it is a condition which further investigation will probably extend to many genera." The only character which is left is the second, and it appears to me questionable whether, on account of such a feature, a single species in all other respects Tetrastemma-like should be raised to the rank of a separate genus.

\section{Prosorhochmus Claparedi, Keferstein.}

Several specimens have been dredged, some from the Millbay Channel, others from the Duke Rock. None of these specimens 
agreed with the figure given by McIntosh either in colour or in general appearance.

The length varied from $8 \mathrm{~mm}$. to $3 \mathrm{~cm}$. The ground colour was a yellowish brown. This on the dorsal surface was covered by a thick uniform sprinkling of reddish-brown grains of pigment. The cephalic grooves were very pronounced. The region included between the anterior and posterior grooves was rendered conspicuous dorsally by the strong development of the reddish-brown pigment, which was here in the form of thick lines radiating forwards in all directions from a median and posterior point. The head, which was broad and conspicuous, in front of the anterior grooves was covered superficially on each side by large flakes of white pigment, which reappeared at the posterior end of the body, covering the tail. The anterior eyes were red, large, and irregularly triangular; the posterior were much smaller and rounder, and were generally closer together than the anterior, though there was sometimes little difference in this respect. The right and left lobes of the snout were very conspicuous, but the transverse dorsal lobe was more difficult to make out.

The stylet region of the proboscis, which is very characteristic, entirely agreed with the figure given by McIntosh.

The shape of the body renders this species at once recognisable. It is constricted behind the posterior grooves, gradually increases in girth up to the middle of its length, and from thence tapers to the tail.

Ripe specimens have been met with in the spring, but I have never seen a female with developing eggs.

Hubrecht did not find this species at Naples, but it was found at Trieste by Dewoletzky. It is rare at Roscoff (Joubin).

\section{Family NEMERTID $\AA$, Hubrecht.}

\section{Genus NEMERTES, Cuvier.}

20. N. GRACILIS, Johnston.

Not uncommon. Almost restricted to the Breakwater, where it is found at low tide among the roots of Laminaria and in the cavities of stones. It has a wide distribution, ranging from the north of England to Madeira. 


\section{N. Neesir, Oersted, McIntosh.}

Like the last, this species abounds on the Breakwater, and is scarcely found elsewhere.

The generative organs are ripe from March to October. Large numbers of eggs have been laid in my dishes, but they have always died without segmenting, though numbers of ripe males were present. Artificial fertilization has been equally a failure.

Like the last, this species is widely distributed, ranging from Iceland to the Mediterranean. It is rare at Naples according to Hubrecht.

\section{Family MALACOBDELLIDA, $v$. Kennel.}

Genus MALACOBDELLA, Blainv.

\section{M. Grossa, Blainv.}

Several specimens of this interesting parasite have been obtained. In all cases they have been found in the branchial cavity of Cyprina islandica. In only one case have I examined one of these molluses without finding a specimen, and in no case has more than one been found in a single Cyprina.

This species lives well in captivity in spite of its parasitic habits. One specimen has lived in a vessel of water submerged in a tank for more than three months, and is still apparently healthy. It moves slowly about the sides of the vessel, to which it adheres by its sucker.

In the autumn many ripe females were found, which subsequently laid unfertilized eggs, but no ripe males have been seen.

\section{Order 4.-HETERONEMERTINI, Bürger.}

The lateral nerves situated, as in the Protonemertini, outside the circular muscular layer. Their apparent position, however, is different, owing to the appearance of a new muscular layer (longitudinal) which has inserted itself between the basement membrane and the circular layer. The lateral nerves are situated between this layer and the circular layer.

The body-wall consists of epidermis, cutis, outer longitudinal muscular layer (new), a circular muscular layer, and an inner longitudinal muscular layer.

Mouth situated behind brain.

Proboscis without a stylet. 


\section{Family LINEID A, McIntosh.}

A. AMICRURAE, Bürger.

Caudal process absent.

Genus LINEUS, Sowerby.

\section{L. Longissimus (Gunn, Sowerby).}

L. MARINUs, McIntosh.

Not very abundant. Occasionally dredged at the Yealm among Phallusia and other Ascidians, and in the deeper water outside the Breakwater. Sometimes found shore-hunting during very low tides among the roots of Laminaria. No specimens have been met with of the size given by McIntosh, the largest not being more than six feet long, while the majority are very much less. Apparently a northern form, as it occurs on the coasts of Norway and Belgium and the Atlantic coasts of France, but not in the Mediterranean.

\section{L. obscurus, Desor.}
L. Gesserensis, McIntosh.
L. SANGUINEUS, McIntosh.
L. GESSERENSIS, Joubin.

By far the commonest Nemertine in the Sound. It is to be found everywhere between tide-marks. Joubin describes five colour varieties: ( $a$ ) deep blue and black; $(b)$ deep olive-green; $(c)$ pure green; $(d)$ green and red; and $(e)$ red. All these varieties, with the exception perhaps of the third, I have met with in the Sound, but I have not noticed that any particular habitat is characteristic of any individual variety. In common with Hubrecht and Joubin, I regard the $L$. gesserensis and sanguineus of McIntosh as varieties of the same species.

Neither Hubrecht nor Bürger has found this species in the Mediterranean, but Joubin appears to have obtained it at Porte Vendres, and Dewoletzky at Trieste. It is, however, like $L$. longissimus, a northern form, though it has a greater southern extension than the latter.

According to McIntosh the breeding season lasts from January to May. Mr. Garstang tells me that during the present year he has found eggs and ripe specimens as early as January, and they are still (March) to be obtained. 


\section{L. Lacteus, Montagu.}

This species seems commoner in the Mediterranean than on the Atlantic shores; at least Joubin states that it is commoner at Banyuls than at Roscoff, and Bürger describes it as "tolerably common" at Naples, though Hubrecht does not seem to have found it there. I have not obtained many specimens. The north side of Drake's Island, between tide-marks, seems the most favorable locality, though isolated specimens have also been obtained in Cawsand Bay. All the individuals were small, measuring only from 5 to $10 \mathrm{~cm}$. in length, whereas those described by McIntosh were one or two feet. I have not met with either ripe specimens or eggs. At Banyuls they are said to breed towards the end of May.

\section{L. Bilineatus, Renier.}

Cerberatulus bilineatus, Hubrecht.

Lineus Binineatus, McIntosh.

Fairly common in from 5 to 20 fathoms. It is especially abundant at the Duke Rock among the shells and stones, though numbers of individuals have been obtained from the west channel and elsewhere. One small specimen was obtained among corallines in tide-pools on the east side of Drake's Island. It is the dark-coloured specimen mentioned below. The greater number of the specimens which I have seen are small, being only from 3 to $5 \mathrm{~cm}$. long. Only one was a fair size. This was dredged at the Duke Rock on May 14th. Its length could not be determined, as its tail was missing, but its breadth was $0.5 \mathrm{~cm}$, so that its length when complete must have been at least 12 to $15 \mathrm{~cm}$.

This species is very variable in colour. The majority of individuals were of a creamy white, inclining to reddishness. In some the brown-red pigment granules were localised in patches here and there. As the larger specimens almost invariably showed more colour than the smaller, I was inclined at first to think that these differences indicated merely stages in development. The finding, however, of a very small specimen between 2 and $3 \mathrm{~cm}$. long, which was of a dark uniform chocolate-brown, seems to point rather to colour variation as the explanation, and this is strengthened by the fact that I have found specimens $4 \mathrm{~cm}$. long perfectly white. The colour of the single large specimen was a beautiful dark purple.

In all the specimens I have seen the dorso-median line is double, being divided by a thin line of the same colour as that diffused over the body. Those described by Bürger from Naples are without the median dividing line, though Hubrecht has found there specimens 
quite typical in this respect. According to Chapuis this is a viviparous species. Dalyell, however, states that his specimens laid vast quantities of eggs in June. Unfortunately I have been unable to make any observations on this point.

\section{B. MICRURA, Bürger.}

A caudal appendage present.

\section{Genus MICRURA, Ehrenberg, Bürger.}

Includes small forms with tapering head not marked off from body. Progression by crawling, not swimming. Usually knotted in heaps or strongly contracted. Provided with a caudal appendage.

\section{M. purpurea (Dalyell), J. Müller.}

Cerebratulus purpureds, Hubrecht.

A common species, dredged in 5 to 20 fathoms. The Duke Rock appears a specially favorable locality. All specimens so far met with are rather small, the largest not exceeding $5 \mathrm{~cm}$. I have never found a specimen with eyes, but Joubin says that a large specimen which he obtained had a dozen extremely small eyes, which were situated on the yellow band across the snout. The ground colour is very variable, all shades of red and brown being represented as well as purple. A single light green specimen was dredged outside the Breakwater on November 7th. I have not as yet met with any ripe specimens, but Joubin records the capture of one containing eggs in June, and McIntosh in April. The voracity of this species is mentioned by McIntosh ; I met with a striking instance of it in May last. A specimen of about 3 or $4 \mathrm{~cm}$. was placed in a dish with a Nemertes Neesii of quite $20 \mathrm{~cm}$. length. Some little time after I was astonished to find the Micrura busily engaged in swallowing the Nemertes. The posterior one fifth of the latter had already disappeared into the mouth of the former when I noticed them, and still the assailant was struggling to gulp down more of its prey. In the meantime the victim glided round the dish, apparently not suffering the smallest inconvenience from the attack upon its posterior extremity. Ultimately both attacker and attacked became quiescent, the former having become more than twice its previous girth. The portion of the Nemertes in the gut of the Micrura still remained in continuity with the rest of the body, though apparently undergoing digestion. 
28. M. aurantiaca, Grube.

\section{Cerebratulus aurantiacus, Hubrecht.}

One individual only has been obtained. This was found between tide-marks at Wembury Bay on June 10th. The length was only from 3 to $4 \mathrm{~cm}$., the colour bright vermilion dorsally, ventrally pale pink. Dorsally the vermilion was interrupted on each side of the middle line over a region corresponding to the hinder quarter of the cephalic slits, in such a way as to cause the appearance of a neck, the pale unpigmented edges being almost invisible in comparison with the median strongly pigmented portion. Two white patches were present, one on each side of the snout, of considerable vertical depth, as when the worm was examined laterally the white patches were seen to pass from the dorsal to the ventral lips of the cephalic slits. In the figure given by McIntosh of this species there is a single crescentic white patch, and the region in front of the crescent is pigmented like the body. In my specimen, however, not only is the patch double, but there is no pigmented region in front of it, the snout being anteriorly devoid of pigment. Eyes absent. Cephalic slits elongate and deep.

No caudal appendage was observed in this individual. This was, curiously enough, the case in the specimen described by McIntosh, for though the caudal appendage was figured by the artist, the writer states that he did not himself observe it.

Although many colour varieties of this species have been recorded, none, I believe, have been found with the anterior white patches distributed in the way above described.

This species is new to the British coast, not having been recorded further north than the island of Herm.

\section{M. fasciolata, Ehrenberg.}

\section{Cerebratulus fasciolatus, Hubrecht.}

This very pretty species is common in the Sound, great numbers being dredged, especially at the Duke Rock. Many varieties of different shades of red have been collected, but no green varieties, which seem to be the most abundant at Naples.

One specimen from the Duke Rock was interesting as an example of the regenerative power of this species. The whole animal was twice as long as its own cephalic slits; one transverse white band was present in the usual position of the first band, and accurately marked the middle of the animal. The head was of the size of that of a specimen of 3 or $4 \mathrm{~cm}$. Just before the posterior termination 
of the body there was a sudden reduction in girth, followed by the usual caudal appendage.

Ripe individuals are found from October to the end of the year.

30. M. CANDIDA, Bürger.

Nemertes lactea.

Cerebratulus lacteus, Hubrecht.

I refer to this species a Nemertine which was dredged at Stoke Point on the 10th of November. It was $1.5 \mathrm{~cm}$. long, of an opaque white colour, and possessed a caudal appendage. Eyes seemed to be absent. Unfortunately while under observation the animal died, its body rupturing in an extraordinary manner, and from no ascertainable cause, and emitting clouds of spermatozoa.

This species has not previously been recorded in Great Britain; it is common at Naples, and occasionally found at Banyuls and Roscoff, but the absolutely white variety seems to be rare on the French coast.

\section{Genus CEREBRATULUS, Renier, Bürger.}

Relatively broad, powerful forms, which roll themselves spirally and do not tie themselves in knots. They are excellent swimmers, cutting through the water in an eel-like manner. In transverse section the body forms a long ellipse. The lateral edges of the body stand out like longitudinal folds. Head lancet-shaped, All have a caudal appendage.

\section{C. Fuscus, McIntosh, Hubrecht.}

\section{Miordra rUsca, MoIntosh.}

A few specimens only have been obtained. The first was dredged in 4 or 5 fathoms in Jennycliff Bay on November 30th, a few others were dredged between the Mallard and Cobbler Rocks. Of these specimens the smallest was $2 \mathrm{~cm}$. in length, and the largest 5 $\mathrm{cm}$, the latter being $3 \mathrm{~mm}$. broad at the tail, and the caudal appendage reaching the length of $2.5 \mathrm{~mm}$.

There is much variability in the disposition of the brown flakes of pigment on the yellow ground colour. In some specimens the brown pigment was limited to the head, in others it was present over the whole dorsal surface of the body, but in all cases it was very sparsely if at all distributed on the ventral surface.

The disposition of the eyes is very irregular. In one specimen I counted eight eyes. Two of these were situated in corresponding 
positions on each side of the snout, and were about four times as large as the rest. Of the remainder two were placed on the left side and four on the right, but there was no kind of regularity in their arrangement.

Joubin's figure (Pl. XXX, fig. 3) shows well the peculiar posterior end so characteristic of this species. The nervous system is conspicuously red.

32. C. pantherinus, Hubrecht.

C. Marginatus (pars), Joubin.

I assign to this species a Cerebratulus dredged off Stoke Point on September 4th.

In colour it agreed with the last species, from which it differed in the shape of the head, the absence of eyes, and in the posterior termination of the body. The anterior end was much swollen, and waves of contraction continually passed along the whole length of the animal. When it reached me it was extremely sluggish, exhibiting no other sign of life than these contractions. The snout was very pointed, and the cephalic slits were deep with closely opposed lips. Posteriorly the lips were opened, exhibiting deep pits leading to the side organs. At this point the slits were red. The animal, which was $4 \mathrm{~cm}$. in length, was a ripe male. The testes were present in a series from the blunt tail to the anterior fifth of the body. The mouth was a large corrugated slit just behind the cephalic slits. The brain, which was situated just in front of the region where the cephalic slits widen out, showed through the ventral wall of the body and through the slits, laterally, as a bright red body.

Joubin regards this species as a variety of $C$. marginatus, but Bürger, who has obtained many specimens of both, is convinced of its validity, stating that all the forms which are pigmented in the manner characteristic of this species differ from O. marginatus in the structure of the brain.

I am not sure whether this species is included by McIntosh as a variety of $C$. angulatus. If not, this is its first record in Great Britain.

This is another of the deep water species, which are, no doubt, more common than they seem, but which are at present nearly inaccessible to us. 


\section{References.}

1. McIntosh, W. C.-A Monograph of British Annelids. Part I, Nemertines.

2. Hubrecht.-Genera and Species of European Nemertines, Notes from Leyden Museum, xliv.

3. " "Challenger" Report on Nemertea.

4. Joubin.-Sur les Turbellariés des Cótes de France, Arch. Zool. exp. et gén., 2me série, viii, 1890.

5. BüRGRR.-Ueber die Anatomie u. Histologie der Nemertinen nebst Beiträgen zur Systematik, Z. f. w. Z., xv, 1890.

6. „ Vorläufige Mittheilungen über Untersuchungen an Nemertinen des Golfes von Neapel, Nachrichten v. d. K. Gesellschaft d. Wissenschaften zu Göttingen, 1891.

7. „ Zur Systematik der Nemertinen fauna des Golfes Neapel, ibid., March, 1892.

8. Carus, J. V.-Prodromus Mediterranex.

9. Barrors, J.-L'Embryologie des Nemertes, Paris, 1877.

10. Dгкск.-Anatomie $u$. Ontogenie der Cephalothrix Galatheæ, Jenaische Zeitschrift, Bd. viii, 1874.

11. Du Plessis, G.-Sur une nouvelle Oerstedia aveugle mais portant une paire de vésicules auditives, Z. Anzeiger, 14 Jahrg., pp. 413-16, 1891. 